\title{
Article \\ Beta Lactams Plus Daptomycin Combination Therapy for Infective Endocarditis: An Italian National Survey (BADAS)
}

\author{
Silvia Corcione ${ }^{1,2}$, Tommaso Lupia ${ }^{3, *(\mathbb{D})}$, Carlo Pallotto ${ }^{4}\left(\mathbb{D}\right.$, Daniele Roberto Giacobbe ${ }^{5,6}$ (D), Ilaria De Benedetto ${ }^{1}$, \\ Giacomo Stroffolini ${ }^{1}{ }^{1}$, Simone Mornese Pinna ${ }^{1}$, Carlo Tascini ${ }^{7,8} \mathbb{C D}$, Matteo Bassetti ${ }^{5,6}$, \\ Francesco Giuseppe De Rosa ${ }^{1,3}$ and on behalf of SITA GIOVANI (Young Investigators Group of the \\ Società Italiana Terapia Antinfettiva) ${ }^{\dagger}$
}

check for updates

Citation: Corcione, S.; Lupia, T.; Pallotto, C.; Giacobbe, D.R.; De Benedetto, I.; Stroffolini, G.;

Mornese Pinna, S.; Tascini, C.; Bassetti, M.; De Rosa, F.G.; et al. Beta Lactams Plus Daptomycin Combination Therapy for Infective Endocarditis: An Italian National Survey (BADAS). Antibiotics 2022, 11, 56. https://doi.org/10.3390/ antibiotics 11010056

Academic Editor: Majdi N. Al-Hasan

Received: 16 October 2021

Accepted: 28 December 2021

Published: 2 January 2022

Publisher's Note: MDPI stays neutral with regard to jurisdictional claims in published maps and institutional affiliations.

Copyright: (C) 2022 by the authors. Licensee MDPI, Basel, Switzerland. This article is an open access article distributed under the terms and conditions of the Creative Commons Attribution (CC BY) license (https:// creativecommons.org/licenses/by/ $4.0 /)$.
1 Department of Medical Sciences, University of Turin, 10126 Turin, Italy; silvia.corcione@unito.it (S.C.); ilaria.debenedetto@unito.it (I.D.B.); giacomo.stroffolini@unito.it (G.S.); simone.mornesepinna@unito.it (S.M.P.); francescogiuseppe.derosa@unito.it (F.G.D.R.)

2 Department of Infectious Diseases, Tufts University School of Medicine, Boston, MA 02129, USA

3 Infectious Diseases Unit, Cardinal Massaia Hospital, 14100 Asti, Italy

4 Infectious Diseases Unit, University Hospital of Perugia, 06156 Perugia, Italy; pallottoc@gmail.com

5 Department of Health Sciences (DISSAL), University of Genoa, 16132 Genoa, Italy; danieleroberto.giacobbe@unige.it (D.R.G.); matteo.bassetti@unige.it (M.B.)

6 Clinica Malattie Infettive, San Martino Policlinico Hospital-IRCCS for Oncology and Neurosciences, 16132 Genoa, Italy

7 Department of Medicine, University of Udine, 33100 Udine, Italy; c.tascini@gmail.com

8 Infectious Diseases Clinic, Udine University Hospital, 33100 Udine, Italy

* Correspondence: tommaso.lupia89@gmail.com; Tel.: +39-0141486404 or +39-3462248637

$\dagger$ Membership of the ELANS Study Group is provided in the Acknowledgments.

\begin{abstract}
Background: infective endocarditis (IE) remains a severe disease frequently encountered in clinical practice and often requiring interdisciplinary medical and surgical management. This national survey aims to describe the clinical prescribing habits of the use of daptomycin in the setting of IE and the possible role for combination therapy with beta-lactams. Methods: The study was a cross-sectional internet-based questionnaire survey on therapy with daptomycin. The questionnaire was designed with closed-ended questions and distributed using the SurveyMonkey ${ }^{\circledR}$ platform between October 2019 to December 2020. Results: 55 clinicians from twelve Italians regions joined the questionnaire. The survey reported use of daptomycin as first-line choice in $31.48 \%$ of cases and as the first-line anti-MRSA agent in $44.44 \%$. The empiric use of daptomycin was stated in the high suspicion of MRSA rather than MSSA, enterococcal or streptococcal IE. The rationale of daptomycin for the empirical treatment of native and prosthetic valve IE was mostly the possibility of administering an aminoglycoside-sparing combination regimen, high bacterial killing rate and high clinical efficacy. Conclusions: In conclusion, in selected patients, daptomycin could be a feasible option for the treatment of infective endocarditis in line with data from the European registry of daptomycin.
\end{abstract}

Keywords: endocarditis; daptomycin; combination therapy; survey; gram-positive

\section{Introduction}

Infective endocarditis (IE) remains a severe disease frequently encountered in clinical practice and often requiring interdisciplinary medical and surgical management [1-5].

Recently, the European Society of Cardiology (ESC) EURObservational Research Programme (EORP) implemented the European Endocarditis (EURO-ENDO) international registry, confirming the high prevalence of gram-positive microorganisms involved in both native and prosthetic valve endocarditis [6,7]: Staphylococcus spp., oral streptococci, Enterococcus spp., and Streptococcus gallolyticus are the most common pathogens in this registry $[6,7]$. 
Furthermore, the IE population has been transforming, with increasing incidence in elderly adults, highly comorbid patients and prosthetic heart valve cases $[1-3,6,7]$. IE populations often have multiple comorbidities, such as cardiovascular diseases, diabetes mellitus, cancer, and chronic liver and kidney diseases [1-3,6,7]. IE in this population requires effective and manageable therapies according to the frailty. Frail patients are characterized by high morbidity and mortality and puts the subjects at greater risk of developing adverse antibiotic effects [1-3,6,7].

Daptomycin, a lipopeptide antimicrobial with concentration-dependent bactericidal activity against gram-positive organisms, including antimicrobial-resistant pathogens such as methicillin-resistant Staphylococcus aureus (MRSA), is approved for treating complicated skin and soft tissue infections [CSSSI], furthermore clinical experiences and preliminary data are increasing and are favourable to treating osteoarticular infections [8]. Daptomycin was originally found non-inferior to standard therapy for $S$. aureus bacteremia and right-sided endocarditis at the daily dose of $6 \mathrm{mg} / \mathrm{kg}$. [9]. Later on, Daptomycin was successfully used at median dose of $5.93 \mathrm{mg} / \mathrm{kg}$ for vancomycin-resistant Enterococcus spp. (VRE) bloodstream infections, and it has been recently used in the therapy of both left and rightsided IE [10-12]. Nevertheless, the use of standard dosing of $6 \mathrm{mg} / \mathrm{kg}$ once-daily has led to the emergence of resistant strains associated with clinical failures and, more recently, higher doses (8-12 mg/ kg once daily) provided improved effectiveness in the treatment of Gram-positive endocarditis [10-12].

Considering daptomycin in IE treatment represents an option to encourage aminoglycoside and glycopeptide sparing strategy in order to avoid renal damage, especially in elderly comorbid population [12,13]. Moreover, daptomycin has been demonstrated safe and effective when vancomycin minimum inhibitory concentration (MIC) values rise above $1 \mathrm{mg} / \mathrm{L}$ obtaining faster clearance of bacteremia and lower rates of clinical failure [14] Observational and randomized controlled trials suggested the combination of daptomycin with a beta-lactam in patients with MRSA bacteremia [15-18] Nonetheless, a recent metanalysis including 1636 patients in this setting showing higher cure rates with the combination therapy failed to demonstrate a difference in mortality rates or renal damage because of the heterogeneity in the choice of the beta-lactam [19]. Finally, some uncertainty on the daptomycin combination therapy with beta-lactams remains in the contest of IE.

This national survey aims to describe the clinical prescribing habits of the use of daptomycin in the setting of IE and the possible role for combination therapy with betalactams.

\section{Results}

Fifty-five clinicians joined the questionnaire through electronic mail. The hospitals and clinicians involved are distributed in twelve Italian regions (Calabria Campania, EmiliaRomagna, Friuli Venezia Giulia, Lazio, Liguria, Lombardia, Liguria, Toscana, Piemonte, Sicilia, Umbria and Veneto). Of these, 21.85\% (28) were university hospitals, 9.26\% (5) were base, $29.63 \%$ (16) were first, and 9.26\% (5) were second-level care hospitals. The main features of centers involved in the survey are described in Table 1 . The number of beds in each center was, for the relative majority, higher than $500(50.91 \%$; 28), followed by 200-500 $(36.36 \% ; 20), 100-200(7.27 \% ; 4)$, and fewer than 100 beds $(5.45 \% ; 3)$. The majority of the hospitals $(59.26 \%$; 32) had high-risk units on-site with $18.52 \%$ (10) being cardiosurgical, $12.96 \%$ (7) solid organ transplant, 5.56\% (3) (Table 1). 
Table 1. Features of the centers enrolled in the survey.

\begin{tabular}{|c|c|c|c|c|}
\hline Type of Hospital & University & Base Level & I Level & II Level \\
\hline (Responding 54/55 partecipants) & $28(51.85 \%)$ & $5(9.26)$ & $16(29.63)$ & $5(9.26)$ \\
\hline Number of beds & $<100$ & $100-200$ & $200-500$ & $>500$ \\
\hline (Responding 55/55 partecipants) & $3(5.45 \%)$ & $4(7.27)$ & $20(36.36)$ & $28(50.91)$ \\
\hline Intensive Care Unit in-hospital & No & Yes & & \\
\hline \multirow[t]{7}{*}{ (Responding 55/55 partecipants) } & $2(3.64 \%)$ & $53(96.36)$ & & \\
\hline & & YES categor & & \\
\hline & & /cardio; $16(3$ & & \\
\hline & & H/neuro; 6 (11 & & \\
\hline & & Burn; 1 (1.88 & & \\
\hline & & nsplant; 5 (9. & & \\
\hline & & diatric; $3(5.6$ & & \\
\hline High Risk Unit in-hospital & No & Yes & & \\
\hline \multirow[t]{7}{*}{ (Responding 54/55 partecipants) } & $32(59.26 \%)$ & $22(40.74)$ & & \\
\hline & & YES categor & & \\
\hline & & natologic; 3 & & \\
\hline & & OT; $7(12.96$ & & \\
\hline & & diatric; 1 (1.8 & & \\
\hline & & $\mathrm{NCH} ; 1(1.85$ & & \\
\hline & & $\mathrm{CH} ; 10(18.5$ & & \\
\hline
\end{tabular}

$\mathrm{CCH}$ : cardiac surgery; $\mathrm{NCH}$ : neurosurgery; SOT: solid organ transplant.

An in-hospital infectious disease (ID) consultant was available in $(29.63 \%$ (16) of the hospitals, and a consultant and ID unit was present in 66.67\% (36) (Table 2).

Table 2. Information regarding infectious disease specialist and infection control procedures.

\begin{tabular}{|c|c|c|c|c|}
\hline ID Consultant & In-Hospital & In-Hospital with ID Unit & On-Call & No ID \\
\hline (Responding 54/55 partecipants) & $16(29.63 \%)$ & $36(66.67)$ & $1(1.85)$ & $1(1.85)$ \\
\hline Infection Comitee in the Hospital & No & Yes & & \\
\hline (Responding 54/55 partecipants) & $1(1.85 \%)$ & $53(98.15)$ & & \\
\hline Alert systems for MDROs & No & Yes & & \\
\hline (Responding 54/55 partecipants) & $42(77.78 \%)$ & $12(22.22)$ & & \\
\hline Available epidemiological MDRO's data & No & Yes & & \\
\hline (Responding 54/55 partecipants) & $2(3.70 \%)$ & $54(96.3)$ & & \\
\hline Presence of antibiotic GL & No & Yes & Regional GL & Hospital GL \\
\hline (Responding 54/55 partecipants) & $19(35.19 \%)$ & $35(64.81)$ & $10(28.57)$ & $25(71.43)$ \\
\hline
\end{tabular}

ID: Infectious Diseases; MDROs: multi-drug resistant organisms; GL: guidelines.

Almost all of the hospitals $(98.15 \% ; 53)$ had an infection committee with access to epidemiological MDRO data $(96.3 \% ; 53)$, and more than half of the participating centres reported the presence of antibiotic guidelines $(64.81 \% ; 35)$, both locally $(71.43 \% ; 25)$ and regionally $(28.57 \%$; 10$)$ (Table 2$)$.

$73.58 \%$ of center reported an incidence of $<50$ cases of IE/year (Table 3). Cardiosurgical service was available in $59.26 \%$ (32) hospitals, whilst the endocarditis team was reported in $70 \%$ (37) of them (Table 3). 
Table 3. Incidence on endocarditis management from enrolled hospitals.

\begin{tabular}{|c|c|c|c|}
\hline IE Per Years & $>50$ Years & $<50$ Years & \\
\hline (Responding 53/55 partecipants) & $14(26.42 \%)$ & $39(73.58)$ & \\
\hline Presence of Endocarditis Team & No & Yes & \\
\hline (Responding 53/55 partecipants) & $37(69.81 \%)$ & $16(30.19)$ & \\
\hline Presence of $\mathrm{CCH}$ & No & Yes & \\
\hline (Responding 54/55 partecipants) & $22(40.74 \%)$ & $32(59.26)$ & \\
\hline Prescription of ABX in IE & ID & Physician & Both \\
\hline (Responding 53/55 partecipants) & $34(62.97 \%)$ & $1(1.85)$ & $18(33.33)$ \\
\hline Empiric ABX in IE Native Valve & Combination & Monotherapy & \\
\hline Total & $42(77.77 \%)$ & $12(22.22)$ & \\
\hline Including always Vancomycin & $3(5.55 \%)$ & & \\
\hline Including always $A G$ & $1(1.88 \%)$ & & \\
\hline Empiric ABX in IE Protesic Valve & Combination & Monotherapy & \\
\hline Total & $45(83.33 \%)$ & $1(1.85)$ & \\
\hline Including always Vancomycin & $3(5.88 \%)$ & & \\
\hline Including always $A G$ & $2(3.92 \%)$ & & \\
\hline Duration of treatment (No need for $\mathrm{CCH}$ ) & $\begin{array}{c}<6 \text { wks (according } \\
\text { to isolated) }\end{array}$ & $\begin{array}{c}>6 \text { wks (indipendent } \\
\text { to isolated) }\end{array}$ & \\
\hline (Responding 54/55 partecipants) & $45(83.33 \%)$ & $9(16.67)$ & \\
\hline Duration of treatment (Need for $\mathrm{CCH}$ ) & $\begin{array}{c}<6 \text { wks (according } \\
\text { to isolated) }\end{array}$ & $\begin{array}{c}>6 \text { wks (indipendent } \\
\text { to isolated) }\end{array}$ & \\
\hline (Responding 54/55 partecipants) & $45(83.33 \%)$ & $9(16.67)$ & \\
\hline Duration of treatment & IE Native Valve & IE Protesic Valve & \\
\hline Median (IQR) & $4(2-89)$ wks & $6(4-12)$ & \\
\hline
\end{tabular}

IE: infective endocarditis; ABX: antibiotics; $\mathrm{CCH}$ : cardiac surgery; AG: aminoglycoside.

The ID consultant was responsible for prescribing empiric antibiotic IE therapy in $62.97 \%$ (34) of the hospitals (Table 3). The preferred empirical treatment was more often a combination of antibiotics than monotherapy in both native $77.77 \%$ (42) and prosthetic $83.33 \%$ (45) valve IE. In both IE subtypes, respondents reported regimens always including vancomycin $(5.55 \% ; 3$ and $5.88 \%$; 3 respectively) or aminoglycoside $(1.88 \% ; 1$ and $3.92 \% ; 2$ respectively). The duration of treatment was $\leq 6$ weeks and according to infection isolation rather than $>6$ weeks independent of isolation, either in case of need (43.33\% (45) vs. $16.67 \%$ (9)) or no need $(83.33 \%(45)$ vs. $16.67 \%$ (9)) of cardiosurgical treatment. The median duration of antibiotic treatment in native and prosthetic valve IE was 4 and 6 weeks, respectively (IQR 4-12) (Table 3).

The interviewed clinicians reported the use of daptomycin as first-line choice in $31.48 \%$ (17) of cases and as the first-line anti-MRSA agent in $44.44 \%$ (24). The empiric use of daptomycin was stated in the high suspicion of MRSA $(90.38 \%$; 47$)$ rather than MSSA $(3.85 \% ; 2)$, enterococcal $(5.77 \% ; 3)$, or streptococcal $(0 \%$; 0$)$ IE (Table 4$)$. 
Table 4. Empirical, targeted combination therapy or monotherapy including Daptomycin in different settings: responses from enrolled hospitals.

\begin{tabular}{|c|c|c|c|c|}
\hline Empiric Daptomycin in IE & IE MRSA & IE MSSA & IE Enterococcus & IE Streptococcus \\
\hline (Responding 52/55 partecipants) & $47(90.38)$ & $2(3.85)$ & $3(5.77)$ & $0(0)$ \\
\hline $\begin{array}{c}\text { Ongoing Resistant Streptococcus spp. strains } \\
\text { to Daptomycin }\end{array}$ & No & Yes & & \\
\hline (Responding 52/55 partecipants) & $40(76.92)$ & $12(23.07)$ & & \\
\hline Monotherapy & & $11(91.66)$ & & \\
\hline Combination & & $1(8.34)$ & & \\
\hline Daptomycin in Clinical Practice in IE & $\begin{array}{l}\text { First-line in } \\
\text { Empiric Therapy }\end{array}$ & $\begin{array}{l}\text { First-line in } \\
\text { MRSA IE }\end{array}$ & No First-line & \\
\hline (Responding 53/55 partecipants) & $17(31.48)$ & $24(44.44)$ & $12(24.07)$ & \\
\hline \multicolumn{5}{|l|}{ Daptomycin Empirical in IE (Native Valve) } \\
\hline High Clinical Efficacy & $10(18.87)$ & & & \\
\hline Combination with AG-sparing & $13(24.53)$ & & & \\
\hline High penetration in vegetations & $6(11.32)$ & & & \\
\hline Safety and low toxicity & $3(5.66)$ & & & \\
\hline Single-day administration and OPAT choice & $3(5.66)$ & & & \\
\hline Biofilm acitivity & $5(9.43)$ & & & \\
\hline High bacterial killing rate & $13(24.53)$ & & & \\
\hline Low rate of resistant strains/favourable MICs & $0(0)$ & & & \\
\hline \multicolumn{5}{|l|}{$\begin{array}{l}\text { Daptomycin Empirical in IE } \\
\text { (Prostethic Valve) }\end{array}$} \\
\hline High Clinical Efficacy & $5(9.80)$ & & & \\
\hline Combination with AG-sparing & $5(9.80)$ & & & \\
\hline High penetration in vegetations & $4(7.84)$ & & & \\
\hline Safety and low toxicity & $5(9.80)$ & & & \\
\hline Single-day administration and OPAT choice & $1(1.96)$ & & & \\
\hline Biofilm acitivity & $29(56.86)$ & & & \\
\hline High bacterial killing rate & $2(3.92)$ & & & \\
\hline Low rate of resistant strains/favourable MICs & $0(0)$ & & & \\
\hline \multicolumn{5}{|l|}{ Methods of Daptomycin Using in IE } \\
\hline$(\leq 6 \mathrm{mg} / \mathrm{kg})$ Monotherapy & $0(0)$ & & & \\
\hline$(\leq 6 \mathrm{mg} / \mathrm{kg})$ Combination & $4(7.41)$ & & & \\
\hline (8-10 mg/kg) Monotherapy & $12(22.22)$ & & & \\
\hline (8-10 mg/kg) Combination & $38(70.37)$ & & & \\
\hline \multicolumn{5}{|l|}{ Daptomycin in combination therapy in IE } \\
\hline Rifampin & $5(10.42)$ & & & \\
\hline $\mathrm{AG}$ & $4(8.33)$ & & & \\
\hline Beta-lactams & $26(54.17)$ & & & \\
\hline Cephalosporins (III or IV gen) & $4(8.33)$ & & & \\
\hline Novel Cephalosporins & $9(18.75)$ & & & \\
\hline
\end{tabular}


Table 4. Cont.

\begin{tabular}{|c|c|c|c|c|}
\hline Empiric Daptomycin in IE & IE MRSA & IE MSSA & IE Enterococcus & IE Streptococcus \\
\hline \multicolumn{5}{|l|}{$\begin{array}{l}\text { Daptomycin dose in clinical practice in IE } \\
\text { according to pathogen }\end{array}$} \\
\hline Streptococcus spp. & $0(0)$ & & & \\
\hline MSSA & $0(0)$ & & & \\
\hline MRSA & $33(61.11)$ & & & \\
\hline Both MRSA and MSSA & $9(16.67)$ & & & \\
\hline Enterococcus spp. & $4(7.41)$ & & & \\
\hline Indipendently to pathogens & $8(14.81)$ & & & \\
\hline \multicolumn{5}{|l|}{ Daptomycin plus Beta-lactams in IE } \\
\hline Streptococcus spp. & $0(0)$ & & & \\
\hline MSSA & $2(3.70)$ & & & \\
\hline MRSA & $25(46.30)$ & & & \\
\hline Both MRSA and MSSA & $10(18.52)$ & & & \\
\hline Enterococcus spp. & $10(18.52)$ & & & \\
\hline Indipendently to pathogens & $7(12.96)$ & & & \\
\hline \multicolumn{5}{|l|}{$\begin{array}{c}\text { Daptomycin plus Beta-lactams in IE } \\
\text { (regimens) }\end{array}$} \\
\hline Empiric therapy & $9(16.98)$ & & & \\
\hline Targeted plus OPAT & $14(26.42)$ & & & \\
\hline Targeted then oral de-escalation & $19(35.85)$ & & & \\
\hline Targeted in-hospital (no OPAT) & $11(20.75)$ & & & \\
\hline \multicolumn{5}{|l|}{$\begin{array}{l}\text { De-escalation after Daptomycin therapy in IE } \\
\text { (stable/operated) }\end{array}$} \\
\hline After $1-2$ wks & $22(40.00)$ & & & \\
\hline After 3 wks & $18(32.73)$ & & & \\
\hline After 6 wks & $3(5.45)$ & & & \\
\hline De-escalation is not common in our centre & $12(21.82)$ & & & \\
\hline \multicolumn{5}{|l|}{$\begin{array}{l}\text { Choices for De-escalation } \\
\text { after Daptomycin in IE }\end{array}$} \\
\hline MSSA & Beta-lactams, c & $\begin{array}{l}\text { orins, TMP } \\
\text { ifampicin a }\end{array}$ & $\begin{array}{l}\text { clyndamicin, dox } \\
\text { loroquinolones }\end{array}$ & ycline, doxicycline, \\
\hline MRSA & $\mathrm{TMP} / \mathrm{s}$ & bavancin, li & id, doxicycline anc & rifampicin \\
\hline \multicolumn{5}{|l|}{ Daptomycin interruption or substitution } \\
\hline Partial or no response & $1(1.85)$ & & & \\
\hline Adverse effects & $7(12.96)$ & & & \\
\hline Costs & $3(5.56)$ & & & \\
\hline $\begin{array}{l}\text { Medications more accessible in OPAT or } \\
\text { long-term facility }\end{array}$ & $23(42.59)$ & & & \\
\hline De-escalation & $20(37.04)$ & & & \\
\hline
\end{tabular}

IE: infective endocarditis; MRSA: methicillin-resistant Staphylococcus aureus; MSSA: methicillin-susceptible Staphylococcus aureus; OPAT: outpatient therapy; TMP/SMX: trimethoprim/sulfametoxazole; AG: aminoglycoside; MIC: minimum inhibitory concentration. 
The rationale in the use of daptomycin for the empirical treatment of native and prosthetic valve IE was: the possibility of administering an aminoglycoside-sparing combination regimen $(24.53 \% ; 13$ and $9.80 \%$; , respectively), high bacterial killing rate $(24.53 \%$; $13 \%$ and $3.92 \% ; 2$, respectively); high clinical efficacy $(18.87 \% ; 10$ and $9.80 \% ; 5$, respectively); high vegetation penetration $(11.32 \% ; 6$ and $7.84 \% ; 4$, respectively); biofilm activity $(9.43 \% ; 5$ and $56.86 \%$; 29 , respectively); safety and low toxicity (5.66\%; 3 and $9.80 \%$; 5 respectively); and single-day OPAT administration (5.66\%; 3 and $1.96 \% ; 1$, respectively).

High-dose daptomycin $(8-10 \mathrm{mg} / \mathrm{kg})$ in combination treatment $(70.37 \%$; 38$)$ was preferred. Combination regimens most often included beta-lactams $(54.17 \%$; 26$)$, followed by novel cephalosporins, such as ceftaroline and ceftobiprole $(18.75 \%$; 9$)$, rifampin $(10.42 \%$; $5)$, 3rd- or 4 th-generation cephalosporins $(8.33 \% ; 4)$, or aminoglycosides $(8.33 \% ; 4)$. In targeted therapy, daptomycin was frequently used for MRSA IE $(61.11 \%$; 33), MRSA or MSSA IE (16.67\%; 9), or independently against Streptococcus, MRSA, or MSSA IE (14.81\%; $8)$. It was less commonly used in enterococcal IE $(7.41 \% ; 4)$.

More specifically, daptomycin was considered in combination with beta-lactams more often in MRSA IE $(46.30 \% ; 25)$, MRSA and MSSA IE $(18.52 \% ; 10)$, and independently against Streptococcus, MRSA, or MSSA IE (12.96\%; 7).

A slightly higher use of daptomycin plus beta-lactams over monotherapy was recorded for enterococcal IE $(18.52 \% ; 10)$, and this combination was used, especially as a targeted therapy during hospitalization followed by oral de-escalation $(35.85 \%$; 19$)$ and OPAT with the withdrawal of beta-lactams after discharge $(26.42 \% ; 14)$.

In patients with stable disease or after surgical treatment, de-escalation, stop or switch to monotherapy was considered after $1-2(40.0 \% ; 22)$ or 3 weeks $(32.73 \% ; 18)$ of treatment. For $23 \%$ of the participating hospitals, de-escalation was not routinely performed. Possible de-escalation options were: beta-lactams, cephalosporins, TMP/SMX, clindamycin, doxycycline, rifampin, and fluoroquinolone for MSSA and TMP/SMX, dalbavancin, linezolid, doxycycline, rifampin for MRSA. (Table 4).

\section{Discussion}

Our survey aimed to explore the prescribing habits for the management of IE involving the use of daptomycin, with a particular interest in beta-lactam plus daptomycin combination therapy for IE, as prescribed by ID and internal medicine physicians in Italy between 2019 and 2020.

Respondents from different hospitals located in 13 regions covered homogeneous Italian territory (southern, central and northern Italy). Our results showed that respondents mainly worked within large ( $\geq 500$ beds) university hospitals that frequently included an ICU and neuro/cardio-surgical unit, and they had access to ID consultants or antibiotic guidelines. The incidence of IE appeared to be low, and possibly, as a consequence, endocarditis teams were not widespread in our sample. Interestingly, cardiac-surgeons were largely available in hospitals from which we retrieved data, which may provide a window of opportunity to create endocarditis teams with a multidisciplinary and comprehensive approach, as suggested by current guidelines [1-5]. In fact, the benefit of an endocarditis team has been well established in reducing in-hospital and long-term mortality, improving antimicrobial therapy adherence and reducing deaths caused by embolic events and multiple organ failure. [1-5,20].

Empirical combination therapy was preferred over monotherapy as a starting regimen, regardless of native or prosthetic valve IE. Treatment duration was four to six weeks, with no difference regarding the surgical infection control culture-negative valve. This appears to be in line with IE guidelines [1,2]. Interestingly, almost all respondents considered vancomycin or an aminoglycoside unnecessary in the regimen, providing the opportunity for opening up the possibility of fewer nephrotoxic treatments that spare these molecules. Daptomycin was primarily preferred over other MRSA IE therapies (90\%) and was the first line in the empiric approach in a third of cases. 
Combination therapy, including high-dose daptomycin, was preferred over monotherapy, mainly adding beta-lactams or novel cephalosporins. This data might be explained by the in vitro synergistic effect of these compounds and the emerging data on higher rate of clinical failure associated with the emergence of non-susceptible strains in the contest of infection with high inoculum treated with daptomycin monotherapy, such as MRSA persistent bacteremias [21-23]. In vitro studies reported that combination of daptomycin and $\beta$-lactams could change the superficial charge of cell envelope finally enhancing daptomycin-mediate killing and boosting the cationic antimicrobial peptides-mediate killing even against VRE strains [24,25].

The combination of daptomycin plus beta-lactam in MRSA BSI, especially when including anti-MRSA novel cephalosporins, achieved a clinical success rate ranging from 60 to $100 \%[15,16,18,19,26]$. In another recent study, aminoglycosides were rarely prescribed with daptomycin, and AG-sparing combination regimens were stated as one of the main reasons for choosing daptomycin plus beta-lactams in native IE likely with regard to the synergistic effect in enterococcal etiology. This is noteworthy given the higher mortality rate registered in patients with bacteraemia or IE and renal failure [26,27].

Lower dosage daptomycin was generally less common, both for combination and monotherapy. This can be explained by the fact that higher doses result in achieving better microbiological outcomes. Because of this, many clinicians have stated that the choice of daptomycin is driven by the possibility of achieving good bactericidal, high clinical efficacy and anti-biofilm activity in prosthetic endocarditis.

According to respondents, in one-third of cases, a daptomycin plus beta-lactam regimen after hospitalisation allowed oral de-escalation or attendance at an outpatient antimicrobial therapy clinic (OPAT) with the withdrawal of beta-lactam within one to two weeks for patients with stable disease or after surgical treatment.

In this survey, considered de-escalation options are heterogeneous, including oral [28,29] and long-acting injectable agents, such as dalbavancin, as successfully observed in recent studies [30,31]. Interestingly, for one out of five participants, de-escalation was not commonly performed, probably highlighting difficulties in the follow up of patients outside the hospital setting.

This survey has different limits: respondents have been selected on a voluntary basis from the group of the SITA and not directly from the hospital setting. A possible bias towards respondents who may have a fair knowledge on the subject matter and. By using closed-ended questions to assess the level of knowledge on daptomycin use and IE management, respondents may have selected the most favourable answer instead of using qualitative methods to revel misconceptions.

\section{Materials and Methods}

\subsection{Survey Design}

The study was a cross-sectional internet-based questionnaire survey on therapy with daptomycin. The questionnaire was designed with closed-ended questions and distributed using the SurveyMonkey ${ }^{\circledR}$ platform (San Mateo, CA, United States). We requested information on the participant's specialty, hospital name, and size and type of hospital. Furthermore, we requested information regarding infectious diseases (ID) service in their hospital, antibiotic guidelines and stewardship programmes. Questions on incidence and management of IE caused by different Gram-positive bacteria were submitted to clinicians with focus on monotherapy or combination therapy for IE. Finally, the use of daptomycin, alone or in combination was investigated (the full questionnaire is available in the Supplementary Material Flie S1).

The questionnaire was developed by three primary investigators (TL, SC, CP, CT and FGDR) and pre-tested by all authors for clarity and technical functionality.

Our target population were ID and internal medicine physicians treating patients, giving advice on antibiotic treatment in Italy and members of the Italian Society of Antimicrobial Therapy "Società Italiana di Terapia Anti-infettiva" (SITA and SITA GIOVANI). 
We asked respondents to reply by describing the most common actual practice at their hospital. Only one participant from each hospital was included.

\subsection{Survey Administration}

One investigator submitted the proposal to join the questionnaire through electronic mail. After a positive response, an invitation was sent by the survey coordinator.

Participants were able to access the questionnaire multiple times to allow possible changes and completion later. The survey was voluntary, with no incentives offered to participants (other than being listed as a collaborator).

Participants have had three months (from October 2019 to December 2020) to access the questionnaire.

The survey and the questions did not require a mandatory answer but could also be skipped.

\subsection{Response Rates}

Response rates were calculated as numbers of clinicians from which an answer was recorded. Information on hospital names was used to screen for duplicate entries, but all data were subsequently anonymized for the analyses.

\subsection{Statistical Analysis}

Both completed and partially completed questionnaires were analysed using the number of completed responses per item as the denominator.

\section{Conclusions}

In conclusion, daptomycin could be a feasible option for the treatment of high inoculum intravascular infections (i.e., bacteremia with metastatic complications, endocarditis), especially in selected patients who had a higher risk of MRSA invasive infections, carrying prosthetic valves which required a drug with high bactericidal effect on biofilm [32]. High doses and combination therapy with beta-lactams, including ceftaroline or ceftobiprole, are more likely to be chosen. Moreover, a prospective interventional study comparing daptomycin plus beta-lactams should be considered to evaluate outcomes.

Supplementary Materials: The following supporting information can be downloaded at: https: / / www.mdpi.com/article/10.3390/antibiotics11010056/s1, File S1: full questionnaire.

Author Contributions: Conceptualization, S.C., C.P., T.L., C.T. and F.G.D.R.; methodology, T.L.; software, T.L.; validation, S.C., T.L. and C.P.; formal analysis, T.L.; data curation, T.L. and S.C.; writing-original draft preparation, I.D.B., G.S., S.M.P. and T.L.; writing—review and editing, T.L., S.C., C.P., D.R.G., C.T., M.B. and F.G.D.R.; supervision, C.T., M.B. and F.G.D.R. All authors have read and agreed to the published version of the manuscript.

Funding: This research received no external funding.

Institutional Review Board Statement: Not applicable.

Informed Consent Statement: Not applicable.

Data Availability Statement: The data presented in this study are available on request from the corresponding author.

Acknowledgments: We thanks all the collaborators Alessandro Pandolfo, Alessandra Oliva, Silvia Amadasi, Carlo Torti, Maria Mazzitelli, Maria Laura Stella, Pierluigi Brugnaro, Maddalena Peghin, Alban Rugova, Ivana Paolucci, Cesare Bolla, Gruppo SANE (Stewardship Antimicrobica Negrar), Stefano Di Bella, Erica Franceschini, Daniela Della Gasperina, Matteo Passerini, Alberto Enrico Maraolo, Emanuela Zappulo, Andrea Lombardi, Stefania Piconi, Jacopo Testa, Giovanna Travi, Stefano Quattropanetti, Marco D'Annunzio, Alessandro Russo, Emanuele Delfino, Niccolò Riccardi, Guido Granata, Giulio Viceconte, Danilo Tacconi, Lorenzo Roberto Suardi, Antonio Vena and Sabrina Frattima. 
Conflicts of Interest: The authors declare no conflict of interest.

\section{References}

1. Habib, G.; Lancellotti, P.; Antunes, M.J.; Bongiorni, M.G.; Casalta, J.P.; Del Zotti, F.; Dulgheru, R.; El Khoury, G.; Erba, P.A.; Iung, B.; et al. 2015 ESC Guidelines for the management of infective endocarditis: The Task Force for the Management of Infective Endocarditis of the European Society of Cardiology (ESC). Endorsed by: European Association for Cardio-Thoracic Surgery (EACTS), the European Association of Nuclear Medicine (EANM). Eur. Heart J. 2015, 36, 3075-3128. [PubMed]

2. AATS Surgical Treatment of Infective Endocarditis Consensus Guidelines Writing Committee Chairs; Pettersson, G.B.; Coselli, J.S.; Hussain, S.T.; Griffin, B.; Blackstone, E.H.; Gordon, S.M.; Le Maire, S.A.; Woc-Colburn, L.E. 2016 The American Association for Thoracic Surgery (AATS) consensus guidelines: Surgical treatment of infective endocarditis: Executive summary. J. Thorac. Cardiovasc. Surg. 2017, 153, 1241-1258.e29. [CrossRef] [PubMed]

3. Baumgartner, H.; Falk, V.; Bax, J.J.; De Bonis, M.; Hamm, C.; Holm, P.J.; Iung, B.; Lancellotti, P.; Lansac, E.; Rodriguez Muñoz, D.; et al. 2017 ESC/EACTS Guidelines for the management of valvular heart disease. Eur. Heart J. 2017, 38, 2739-2791. [CrossRef] [PubMed]

4. Botelho-Nevers, E.; Thuny, F.; Casalta, J.P.; Richet, H.; Gouriet, F.; Collart, F.; Riberi, A.; Habib, G.; Raoult, D. Dramatic Reduction in Infective Endocarditis-Related Mortality with a Management-Based Approach. Arch. Intern. Med. 2009, 169, 1290-1298. [CrossRef]

5. Chirillo, F.; Scotton, P.; Rocco, F.; Rigoli, R.; Borsatto, F.; Pedrocco, A.; De Leo, A.; Minniti, G.; Polesel, E.; Olivari, Z. Impact of a Multidisciplinary Management Strategy on the Outcome of Patients with Native Valve Infective Endocarditis. Am. J. Cardiol. 2013, 112, 1171-1176. [CrossRef]

6. Habib, G.; Erba, P.A.; Iung, B.; Donal, E.; Cosyns, B.; Laroche, C.; Popescu, B.A.; Prendergast, B.; Tornos, P.; Sadeghpour, A.; et al. Clinical presentation, aetiology and outcome of infective endocarditis. Results of the ESC-EORP EURO-ENDO (European infective endocarditis) registry: A prospective cohort study. Eur. Heart J. 2019, 40, 3222-3232, Erratum in Eur. Heart J. 2020, 41, 2091. [CrossRef]

7. Habib, G.; Lancellotti, P.; Erba, P.-A.; Sadeghpour, A.; Meshaal, M.; Sambola, A.; Furnaz, S.; Citro, R.; Ternacle, J.; Donal, E.; et al. The ESC-EORP EURO-ENDO (European Infective Endocarditis) registry. Eur. Heart J.-Qual. Care Clin. Outcomes 2019, 5, 202-207, Erratum in Eur. Heart J. Qual. Care Clin. Outcomes 2020, 6, 91. [CrossRef]

8. Malizos, K.; Sarma, J.; Seaton, R.A.; Militz, M.; Menichetti, F.; Riccio, G.; Gaudias, J.; Trostmann, U.; Pathan, R.; Hamed, K. Daptomycin for the treatment of osteomyelitis and orthopaedic device infections: Real-world clinical experience from a European registry. Eur. J. Clin. Microbiol. Infect. Dis. 2016, 35, 111-118. [CrossRef]

9. Fowler, V.G., Jr.; Boucher, H.W.; Corey, G.R.; Abrutyn, E.; Karchmer, A.W.; Rupp, M.E.; Levine, D.P.; Chambers, H.F.; Tally, F.P.; Vigliani, G.A.; et al. Daptomycin versus standard therapy for bacteremia and endocarditis caused by Staphylococcus aureus. N. Engl. J. Med. 2006, 355, 653-665. [CrossRef]

10. Dohmen, P.M.; Guleri, A.; Capone, A.; Utili, R.; Seaton, R.A.; Ramallo, V.J.G.; Pathan, R.; Heep, M.; Chaves, R.L. Daptomycin for the treatment of infective endocarditis: Results from a European registry. J. Antimicrob. Chemother. 2013, 68, 936-942. [CrossRef]

11. Rehm, S.J.; Boucher, H.; Levine, D.; Campion, M.; Eisenstein, B.I.; Vigliani, G.A.; Corey, G.; Abrutyn, E. Daptomycin versus vancomycin plus gentamicin for treatment of bacteraemia and endocarditis due to Staphylococcus aureus: Subset analysis of patients infected with methicillin-resistant isolates. J. Antimicrob. Chemother. 2008, 62, 1413-1421. [CrossRef] [PubMed]

12. Smith, J.R.; Claeys, K.C.; Barber, K.E.; Rybak, M.J. High-Dose Daptomycin Therapy for Staphylococcal Endocarditis and When to Apply It. Curr. Infect. Dis. Rep. 2014, 16, 429. [CrossRef]

13. Carugati, M.; Bayer, A.S.; Miró, J.M.; Park, L.P.; Guimarães, A.C.; Skoutelis, A.; Fortes, C.Q.; Durante-Mangoni, E.; Hannan, M.M.; Nacinovich, F.; et al. High-Dose Daptomycin Therapy for Left-Sided Infective Endocarditis: A Prospective Study from the International Collaboration on Endocarditis. Antimicrob. Agents Chemother. 2013, 57, 6213-6222. [CrossRef] [PubMed]

14. Murray, K.P.; Zhao, J.J.; Davis, S.L.; Kullar, R.; Kaye, K.S.; Lephart, P.; Rybak, M.J. Early Use of Daptomycin Versus Vancomycin for Methicillin-Resistant Staphylococcus aureus Bacteremia With Vancomycin Minimum Inhibitory Concentration >1 mg/L: A Matched Cohort Study. Clin. Infect. Dis. 2013, 56, 1562-1569. [CrossRef]

15. Geriak, M.; Haddad, F.; Rizvi, K.; Rose, W.; Kullar, R.; LaPlante, K.; Yu, M.; Vasina, L.; Ouellette, K.; Zervos, M.; et al. Clinical Data on Daptomycin plus Ceftaroline versus Standard of Care Monotherapy in the Treatment of Methicillin-Resistant Staphylococcus aureus Bacteremia. Antimicrob. Agents Chemother. 2019, 63, e02483-18. [CrossRef] [PubMed]

16. McCreary, E.K.; Kullar, R.; Geriak, M.; Zasowski, E.J.; Rizvi, K.; Schulz, L.T.; Ouellette, K.; Vasina, L.; Haddad, F.; Rybak, M.J.; et al. Multicenter Cohort of Patients With Methicillin-Resistant Staphylococcus aureus Bacteremia Receiving Daptomycin Plus Ceftaroline Compared With Other MRSA Treatments. Open Forum Infect. Dis. 2020, 7, ofz538. [CrossRef]

17. Tong, S.Y.; Lye, D.C.; Yahav, D.; Sud, A.; Robinson, J.O.; Nelson, J.; Archuleta, S.; Roberts, M.A.; Cass, A.; Paterson, D.L.; et al. Effect of vancomycin or daptomycin with vs. without an antistaphylococcal $\beta$-lactam on mortality, bacteremia, relapse, or treatment failure in patients with MRSA bacteremia: A randomized clinical trial. JAMA-J. Am. Med. Assoc. 2020, 323, 527-537. [CrossRef] [PubMed]

18. Jorgensen, S.C.; Zasowski, E.J.; Trinh, T.D.; Lagnf, A.M.; Bhatia, S.; Sabagha, N.; Abdul-Mutakabbir, J.C.; Alosaimy, S.; Mynatt, R.P.; Davis, S.L.; et al. Daptomycin plus $\beta$-lactam combination therapy for methicillin-resistant Staphylococcus aureus bloodstream infections: A retrospective, comparative cohort study. Clin. Infect. Dis. 2019, 71, ciz746. [CrossRef] 
19. Kale-Pradhan, P.B.; Giuliano, C.; Jongekrijg, A.; Rybak, M.J. Combination of Vancomycin or Daptomycin and Beta-lactam Antibiotics: A Meta-analysis. Pharmacother. J. Hum. Pharmacol. Drug Ther. 2020, 40, 648-658. [CrossRef]

20. Crass, R.L.; Powell, K.L.; Huang, A.M. Daptomycin for the treatment of Staphylococcus aureus infections complicated by septic pulmonary emboli. Diagn. Microbiol. Infect. Dis. 2019, 93, 131-135. [CrossRef]

21. Beganovic, M.; Luther, M.K.; Rice, L.B.; Arias, C.A.; Rybak, M.J.; Laplante, K.L. A Review of Combination Antimicrobial Therapy for Enterococcus faecalis Bloodstream Infections and Infective Endocarditis. Clin. Infect. Dis. 2018, 67, 303-309. [CrossRef]

22. Humphries, R.M.; Pollett, S.; Sakoulas, G. A Current Perspective on Daptomycin for the Clinical Microbiologist. Clin. Microbiol. Rev. 2013, 26, 759-780. [CrossRef]

23. Gasch, O.; Camoez, M.; Dominguez, M.A.; Padilla, B.; Pintado, V.; Almirante, B.; Martin, C.; Lopez-Medrano, F.; de Gopegui, E.R.; Blanco, J.R.; et al. Emergence of resistance to daptomycin in a cohort of patients with methicillin-resistant Staphylococcus aureus persistent bacteraemia treated with daptomycin. J. Antimicrob. Chemother. 2014, 69, 568-571. [CrossRef] [PubMed]

24. Sakoulas, G.; Bayer, A.S.; Pogliano, J.; Tsuji, B.T.; Yang, S.-J.; Mishra, N.N.; Nizet, V.; Yeaman, M.R.; Moise, P.A. Ampicillin Enhances Daptomycin- and Cationic Host Defense Peptide-Mediated Killing of Ampicillin- and Vancomycin-Resistant Enterococcus faecium. Antimicrob. Agents Chemother. 2012, 56, 838-844. [CrossRef] [PubMed]

25. Sakoulas, G.; Okumura, C.Y.; Thienphrapa, W.; Olson, J.; Nonejuie, P.; Dam, Q.; Dhand, A.; Pogliano, J.; Yeaman, M.R.; Hensler, M.E.; et al. Nafcillin enhances innate immune-mediated killing of methicillin-resistant Staphylococcus aureus. J. Mol. Med. 2014, 92, 139-149. [CrossRef] [PubMed]

26. Molina, K.C.; Morrisette, T.; Miller, M.A.; Huang, V.; Fish, D.N. The Emerging Role of $\beta$-Lactams in the Treatment of MethicillinResistant Staphylococcus aureus Bloodstream Infections. Antimicrob. Agents Chemother. 2020, 64, e00468-20. [CrossRef]

27. Cecchi, E.; Imazio, M.; De Rosa, F.G.; Chirillo, F.; Enia, F.; Pavan, D.; Cecconi, M.; Squeri, A.; Trinchero, R. Infective endocarditis in the real world: The Italian Registry of Infective Endocarditis (Registro Italiano Endocardite Infettiva-RIEI). J. Cardiovasc. Med. 2008, 9, 508-514. [CrossRef]

28. Iversen, K.; Ihlemann, N.; Gill, S.U.; Madsen, T.; Elming, H.; Jensen, K.T.; Bruun, N.E.; Høfsten, D.E.; Fursted, K.; Christensen, J.J.; et al. Partial Oral versus Intravenous Antibiotic Treatment of Endocarditis. N. Engl. J. Med. 2019, 380, 415-424. [CrossRef]

29. Bundgaard, H.; Ihlemann, N.; Gill, S.U.; Bruun, N.E.; Elming, H.; Madsen, T.; Jensen, K.T.; Fursted, K.; Christensen, J.J.; Schultz, M.; et al. Long-Term Outcomes of Partial Oral Treatment of Endocarditis. N. Engl. J. Med. 2019, 380, 1373-1374. [CrossRef]

30. Hidalgo-Tenorio, C.; Vinuesa, D.; Plata, A.; Martín-Dávila, P.; Iftimie, S.; Sequera, S.; Loeches, B.; Lopez-Cortés, L.E.; Fariñas, M.C.; Fernández-Roldan, C.; et al. DALBACEN cohort: Dalbavancin as consolidation therapy in patients with endocarditis and/or bloodstream infection produced by gram-positive cocci. Ann. Clin. Microbiol. Antimicrob. 2019, 18, 30. [CrossRef]

31. Tobudic, S.; Forstner, C.; Burgmann, H.; Lagler, H.; Ramharter, M.; Steininger, C.; Vossen, M.G.; Winkler, S.; Thalhammer, F. Dalbavancin as Primary and Sequential Treatment for Gram-Positive Infective Endocarditis: 2-Year Experience at the General Hospital of Vienna. Clin. Infect. Dis. 2018, 67, 795-798. [CrossRef] [PubMed]

32. Seaton, R.A.; Gonzalez-Ramallo, V.J.; Prisco, V.; Marcano-Lozada, M.; Gonzalez-Ruiz, A.; Gallegos, B.; Menichetti, F.; Loeffler, J.; Bouylout, K.; Chaves, R.L. Daptomycin for outpatient parenteral antibiotic therapy: A European registry experience. Int. J. Antimicrob. Agents 2013, 41, 468-472. [CrossRef] [PubMed] 